\title{
CRÉDITO FUNDIÁRIO E MERCADO DE TERRAS: CONTRARREFORMA AGRÁRIA DO BANCO MUNDIAL NO CEARÁ - BRASIL
}

\section{CREDITO FUNDIARIO Y MERCADO DE TIERAS: CONTRARREFORMA AGRARIA DEL BANCO MUNDIAL EM CEARÁ - BRASIL}

\section{PROPERTY CREDIT AND LAND MARKET: AGRARIAN COUNTER- REFORM OF THE WORLD BANK IN THE STATE OF CEARÁ - BRAZIL}

\author{
Profa. Alexandra Maria de Oliveira \\ Pós-graduação em Geografia UFC \\ Tutora PET/MEC/SESu
}

\begin{abstract}
Resumo: O texto analisa o credito fundiário (1997-2003) como uma política de contrarreforma agrária do Banco Mundial no Ceará-Brasil. O modelo, baseado na reforma agrária de mercado, foi concebido e difundido pelo governo estadual e federal como uma alternativa à reforma agrária de fato. Inicialmente, apresenta-se o processo mais amplo, demarcando a lógica na qual os programas foram inseridos. Depois, discute-se a inviabilidade socioeconômica da política em assentamentos rurais no Ceará. Por fim, delineia-se a estratégia de fortalecimento do caráter rentista da terra no Estado.
\end{abstract}

Palavras-chaves: Crédito Fundiário. Contrarreforma Agrária. Banco Mundial.

Resumen - El artículo analisa el credito fundiário (1997-2003) como una política de contrareforma agrária del Banco Mundial en el Ceará-Brasil. El modelo, basado en la reforma agraria de mercado, fué concebido y difundido por el gobierno provincial y nacional como una alternativa a la reforma agrária de hecho. Inicialmente, se apresenta como un proceso más amplio, demarcando la lógica en lo cual los programas fuerón incluyedos. Despúes, se discute la inviabilidade socioeconómica de la política en asentamientos rurales en Ceará. Al final, se define la estratégica de fortalecimento del caráter rentista de la terra del Estado.

Palabras-claves: Credito Fundiário. Contrareforma Agrária. Banco Mundial

\begin{abstract}
This paper analyzes the land credit policy (1997-2003) as a policy of agrarian counter-reform of the World Bank in the state of Ceará. The model, based on market agrarian reform, designed and distributed by the state and federal government as an alternative to actual land reform. Initially, it is presented the broader process, bordering the logic in which the programs were inserted. Then we discuss the inviability of socioeconomic policy in rural settlements in the state of Ceará. Finally, it is outlined the strategy of strengthening the rentier character of the land in the state.
\end{abstract}

Keywords: Property Credit; Agrarian Counter-reform; World Bank. 


\section{1 - Introdução}

A política de crédito fundiário é parte do processo de desenvolvimento do capitalismo moderno no campo brasileiro. Esse processo está marcado pela lógica do desenvolvimento desigual e contraditório, pois, ao mesmo tempo em que atua na direção da ampliação do agronegócio, por meio de subsídios e isenções físcais em diferentes regiões do País, tem proporcionado o processo de expansão da agricultura camponesa.

A preocupação do Banco Mundial com a economia dos países em desenvolvimento como o Brasil, o México e a África do Sul tem origem na própria criação da instituição em meados do século XX. O aumento da pobreza no mundo e o endividamento desses países favoreceram as instituições financeiras multilaterais para que elas apresentassem, no final dos anos de 1990, propostas para os setores de educação e desenvolvimento rural. A proposta do Banco Mundial para o "alívio da pobreza" veio com a política de reforma agrária com base no mercado.

O crédito fundiário como uma política de contrarreforma agrária aparece como condição e consequência da forma pela qual o Estado recria o mercado de terras a favor do desenvolvimento capitalista no Ceará. Nesse sentido, a análise sobre a (in)viabilidade socioeconômica da política é também um modo de conhecer alguns liames teóricos e empíricos que compõem a política agrária do Banco Mundial aplicada nos países em desenvolvimento e, em especial, no Brasil a partir de 1996.

\section{2 - O Ceará como vetor inicial da politica de contrarreforma agrária (1997-2003)}

A implantação do crédito fundiário no Ceará aconteceu legalmente em agosto de 1996. Teve como concepção fundante, conforme Binswanger (1996), a "reforma agrária assistida pelo mercado", desenhada pelo Banco Mundial e desenvolvida na África do Sul e na Colômbia.

De acordo com Alencar (2000), a articulação da política no Ceará começou com a Conferência Internacional sobre Impactos de Variações Climáticas e Desenvolvimento Sustentável em Regiões Semiáridas (ICID), que aconteceu em Fortaleza, em 1992, resultando na elaboração do documento intitulado "Projeto Áridas: uma estratégia de desenvolvimento sustentável".

O Projeto Áridas propôs áreas estratégicas que viabilizariam o desenvolvimento sustentável no Nordeste. No que concerne à questão agrária, apresentou o item 2 - 
Ordenamento do espaço regional, com o subprograma "reorganização do meio rural". Para o Áridas, a reforma agrária seria importante desde que

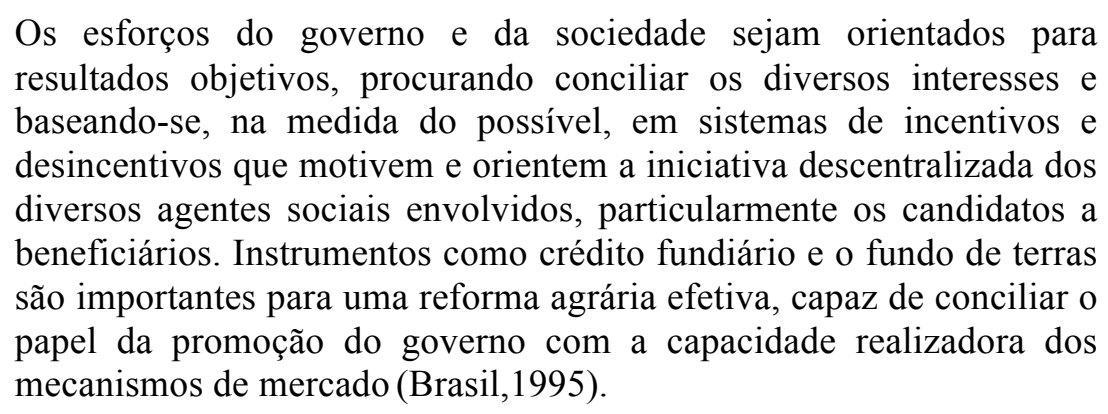

Assim, foram lançadas, no Ceará, as bases do que veio a ser no Nordeste o projeto-piloto Cédula da Terra. Por iniciativa do governador Tasso Jereissati, ocorreram as primeiras reuniões entre representantes do Estado (SDR, IDACE e SEPLAN) e grupo técnico do Banco Mundial. As reuniões realizadas no final de 1995 tiveram como objetivo discutir o planejamento e a implementação de um programa denominado Reforma Agrária Amiga do Mercado, nos moldes de programas semelhantes desenvolvidos na África do Sul e na Colômbia, com o apoio do Banco Mundial.

Com as reuniões, ficou acordado que o Instituto de Desenvolvimento Agrário do Ceará (IDACE) deveria incorporar um componente de ação fundiária ao Projeto São José. Foi criado o fundo rotativo de terras, instituído pela Lei Estadual $n^{\circ} 12.614$, de agosto de 1996, regulamentada pelo Decreto $n^{\circ} 24.239$, de 4 de outubro de 1996. Em fevereiro de 1997, foram concedidos os primeiros financiamentos para aquisição de terra via experiência-piloto, denominada Reforma Agrária Solidária - Projeto São José.

A Reforma Agrária Solidária teve a finalidade de apoiar de forma complementar ações de reforma agrária no Estado, e se destinaria a desenvolver programas de financiamentos reembolsáveis para aquisição de imóveis rurais por pequenos produtores rurais sem-terra e minifundiários, organizados por interesses comuns e representados por associação comunitária legalmente constituída. O fundo de terra financiaria a compra de imóveis rurais apresentados pelos agricultores, por meio das entidades representativas, com o desembolso do valor financiado diretamente na conta do vendedor.

A gestão técnica do fundo de terra estadual ficou a cargo da Secretaria da Agricultura e Pecuária (SEAGRI), por meio do IDACE. A gestão financeira ficou a cargo do Banco do Nordeste do Brasil (BNB) e do Banco do Brasil (BB). 
O fundo foi constituído com recursos provenientes da contrapartida estadual do Projeto de Combate à Pobreza Rural no Ceará - Projeto São José, mediante contrato de empréstimo no 3918 - BR, firmado com o Banco Internacional para Reconstrução e Desenvolvimento (BIRD). Outras foram as fontes de recursos para o fundo de terras: I) recursos financeiros do tesouro estadual e recursos municipais, estaduais, nacionais e internacionais, e II) financiamentos reembolsáveis e sujeitos a pagamento de taxas e encargos previamente definidos, de modo a assegurar a autossustentação do fundo.

A participação dos trabalhadores rurais ficaria assegurada na definição dos imóveis pelos representantes nas instâncias colegiadas do Projeto São José, quais sejam: associações, conselhos comunitários e conselhos consultivos.

O Projeto São José (Ceará, 1987) - Combate à Pobreza no Interior do Ceará foi criado em 1987, com o intuito de "apoiar o pequeno produtor rural, contribuindo na geração de emprego e renda para a população carente do interior". Sua proposta esteve centrada em infraestrutura produtiva - fábrica de doces, casas de farinha, lavanderia comunitária, eletrificação rural - voltada para a geração de emprego e renda.

De acordo com o governo do Estado, a Reforma Agrária Solidária - São José desenvolveria um novo modelo de reestruturação agrária, pelo qual os trabalhadores sem-terra e os minifundiários, organizados em associações, negociariam diretamente a compra de terras.

No processo de negociação, o governo do Estado cederia carta de crédito à associação comunitária para a compra da propriedade rural à vista, independentemente da viabilidade produtiva. As famílias assentadas passariam a dever o valor pago ao proprietário pelo preço da terra ao banco financiador, que cobraria com juros e correção monetária.

A criação do fundo de terras no interior do Projeto São José significou a ampliação dos seus objetivos, descaracterizando sua estrutura inicial. A ideia do fundo de terras desvirtuou completamente a proposta do São José, causando um burburinho no mercado de terras nas áreas do litoral oeste e do sertão central.

Um ano depois do início da operacionalização (1997), a experiência Reforma Agrária Solidária apresentou problemas.

Conforme o ex-deputado estadual do Ceará Eudoro Santana (1997), o governo cearense, ao lançar um programa de reforma agrária, sem conflito, sem violência e com base no mercado, fugiu do problema central da reforma agrária que é a desapropriação 
de terra; com isso, teve o intuito de enfraquecer a luta de movimentos sociais como a CPT e o MST.

O depoimento acima faz parte da leitura de políticos e intelectuais envolvidos com os movimentos socioterritoriais. Nessa leitura, conforme Oliveira (2005), a reforma agrária constitui-se em um conjunto de ações realizadas pelos países capitalistas visando a modificar a estrutura fundiária de uma região ou de um país como um todo. Ela é feita por meio de mudanças na distribuição da propriedade e/ou de posse da terra e da renda com vista a assegurar melhorias sociais, políticas, culturais, técnicas e econômicas, e de reordenamento do território. É uma política que precisa conter a intervenção governamental sob pena de ser inviabilizada. Portanto, falar de reforma agrária solidária é querer levar os trabalhadores a confundir os processos.

$\mathrm{Na}$ leitura do governo estadual descrita por Brandão (2000), dois foram os fatores de sucesso da experiência-piloto Reforma Agrária Solidária - Projeto São José: primeiro, a tentativa do governo de descentralizar a reforma agrária, participando ativamente do processo de democratização da terra e, segundo, o caráter complementar do programa, uma vez que as concessões de financiamento de terras foram complementares às ações de desapropriação de terras.

O sucesso midiático do projeto Reforma Agrária Solidária mais a aliança política entre o governo estadual e o governo federal outorgou investimentos financeiros para ampliar a política no Ceará e expandir a experiência para o Nordeste do País. Isso fez com que os governos programassem, nos Estados do Maranhão, Ceará, Pernambuco, Bahia e área norte de Minas Gerais, o projeto Cédula da Terra - Combate à Pobreza no Meio Rural, o qual manteve no Ceará a denominação Reforma Agrária Solidária Cédula da Terra, operado de 1997 a 2000.

\section{3 - A inviabilidade sócio-econômica da política do crédito fundiário}

O Cédula da Terra (Ceará, 1997) foi a continuidade da experiência desenvolvida em caráter pioneiro pelo governo do Estado do Ceará, por intermédio do Projeto São José. O Cédula caracterizou-se pelos financiamentos de terras e aportes em infraestruturas produtiva e social nas áreas adquiridas para fins de assentamento de trabalhadores rurais sem-terra e minifundiários.

Os requisitos de elegibilidade para a participação no Projeto Cédula da Terra permaneceram os mesmos da experiência antecessora. Mas as condições de 
financiamento definidas foram diferentes: o reembolso passou a ser no prazo de 10 anos, com carência de até três anos, e com aplicação dos encargos previstos (TJLP mais taxa de remuneração do agente financeiro) sobre o saldo devedor.

Além dos recursos para a compra da terra, o Cédula da Terra previa recursos para investimentos comunitários definidos pelo próprio grupo de assentados nos segmentos de infraestrutura, de produção e sociais. Assim, seriam priorizados recuperação de cercas, aumento da capacidade de produção do imóvel, elevação da produtividade e geração de emprego e renda. Nesses investimentos, o financiamento não reembolsável seria de $90 \%$ do valor do recurso, sendo os outros $10 \%$ pagos pelos assentados com o trabalho, com produtos ou em dinheiro, conforme o acordo estabelecido. Com base nesse esquema geral, o projeto piloto CT sofreu adaptações em cada estado, porém sempre mantendo as regras acordadas com o Banco Mundial.

O lançamento do Cédula da Terra no Ceará foi seguido de constantes visitas do ministro Raul Julgmann, em Fortaleza, para entrega de cartas de crédito às associações comunitárias de trabalhadores rurais, e pela visita do diretor do BIRD, sr. Gobim T. Nankani, a assentamento rural no sertão de Iguatu. O resultado das visitas foi a reafirmação do compromisso financeiro do Banco Mundial com a reforma agrária de mercado e o empréstimo de US\$ 1 bilhão para o Brasil, com a possibilidade da criação do Banco da Terra.

A realização do Seminário Internacional "Reforma Agrária e Desenvolvimento Sustentável”, promovido pelo Estado do Ceará e pelo Ministério do Desenvolvimento Agrário, desenvolveu duas frentes de ação. A primeira foi a ação da mídia, que se encarregou de desqualificar o processo de reforma agrária via desapropriação de terras, apresentando os pontos positivos de assentamentos criados pelo modelo de reforma agrária de mercado. A segunda foi a frente intelectual, formada por consultores e técnicos do Banco Mundial, que deram suporte teórico à continuidade da política. Tudo isso colocou o Ceará em evidência no cenário nacional e internacional.

As críticas dos movimentos socioterritoriais à Reforma Agrária de Mercado do Banco Mundial foram, inicialmente, generalizadas. Entre os principais questionamentos, destacam-se: o caráter não complementar do programa; o descaso do Estado para com o processo de desapropriação; a não participação dos movimentos socioterritoriais no planejamento e na execução do programa; o envolvimento de 
proprietários e políticos no processo de constituição das associações, e a incapacidade de pagamento da terra.

Mesmo diante das críticas, o governo Fernando Henrique Cardoso, em visita ao assentamento Cauassu, no Ceará, reafirmou a ampliação do Projeto Cédula da Terra, por meio do lançamento do Banco da Terra. Seguindo a onda de propagação do projeto Reforma Agrária de Mercado, a revista Exame noticiou para o mundo a ocorrência de uma "revolução silenciosa". De acordo com o jornalista Jomar Morais (2000), o Banco da Terra no Ceará estaria mostrando para o mundo um modelo internacional de reforma agrária capitalista. Isso porque "sem conflitos" e sob a bênção dos proprietários fundiários, no novo modelo de reforma agrária adotado no Ceará, os sem-terra estariam virando pequenos empreendedores, livres para tocar seus projetos conforme suas necessidades.

A estratégia do governo estadual de desmobilização dos movimentos sociais e de entidades de representação dos camponeses, inicialmente, deu certo. Sindicatos de esquerda e lideranças de representações camponesas optaram por não se envolver com o programa, partindo do pressuposto de que não seria um projeto social de emancipação dos camponeses.

A leitura do então Secretário do Desenvolvimento Agrícola do Sindicato dos Trabalhadores Rurais (STR) de Canindé foi a seguinte:

O que o governo quer com a reforma agrária solidária é acabar com a luta pela terra. Houve uma grande integração entre os proprietários de terra e os trabalhadores ficaram só com as contas. Por isso, se o Sindicato achasse que era uma reforma agrária social apoiaria, mas o risco maior é que, com a continuidade, se os trabalhadores não pagarem a terra, irão ficar sem terra e devendo ao banco. E os trabalhadores têm de entender que só existe conquista se existir luta. Assim, a 'reforma agrária solidária' será uma conquista para os trabalhadores rurais? Ou irá apenas fazer com que eles apareçam como irresponsáveis diante do banco? (Camponês, 57a. STR Canindé/CE, 2001).

Para o STR de Canindé, a reforma agrária de mercado traria dupla consequência. Primeiro, os trabalhadores ficariam inadimplentes diante do banco, e, segundo, haveria a desmobilização política dos trabalhadores do campo, o que interessaria ao governo.

O convênio firmado entre ABRA, CPT, APR, FIAN-Brasil, MST e REDE Brasil, em 2001, realizou a pesquisa intitulada "a política do Banco Mundial para o setor agrário brasileiro com base no programa Cédula da Terra”, desenvolvida 
simultaneamente em cinco estados: Ceará, Maranhão, Pernambuco, Bahia e Minas Gerais.

De acordo com Alencar et al (2002), os resultados da pesquisa no Ceará apresentaram mudanças positivas e negativas. A autonomia camponesa de liberdade para plantar, e o fato de ter casa para morar, com tijolos, piso de cimento, coberta de telha, banheiro e energia, foram duas grandes conquistas de condições de vida. Por outro lado, a inexistência de água, aliada à baixa fertilidade de solos degradados, estava levando os camponeses ao desencanto com o programa. Com relação às associações pesquisadas, a equipe observou o centralismo do poder de decisão no presidente e que a forma de participação dos membros da associação compreendia apenas assistir às reuniões. Diante da situação, os camponeses se agarravam à esperança e à fé divina para honrar as dívidas provenientes da compra da terra.

O crédito fundiário para o setor agrário brasileiro não foi trabalhado, desde 1997, com prioridade, como ação complementar ou alternativa. Os dados revelaram a competição entre os programas de compra e venda e os de desapropriação por interesse social.

As constatações verificadas na pesquisa feita pela ABRA, CPT, APR, CJG, FIAN-Brasil, MST e REDE Brasil, nos estados contemplados, serviram de base para que o Fórum Social pela Reforma Agrária e Justiça no Campo solicitasse ao Painel de Inspeção do Banco Mundial o pedido de vistoria para o Cédula da Terra.

Com o Banco da Terra funcionando no País, o Ceará saiu de cena, e a política da proposta Reforma Agrária de Mercado se manteve seguindo diretrizes nacionais. Em 2002, período de transição política com eleições presidenciais e governamentais, foi lançado o Crédito Fundiário e Combate à Pobreza rural (CFCP) e, logo em seguida, em 2003, o Programa Nacional de Crédito Fundiário (PNCF). O quadro 01 traz resumo dos programas de crédito fundiário e revela a importância da atuação deles no Estado do Ceará. 


\section{Quadro 01 - Ceará}

Resumo dos Programas São José, Cédula da Terra, Banco da Terra, Crédito Fundiário e Combate à Pobreza rural e Programa Nacional de Crédito Fundiário

Período de 1997 até 2004

\begin{tabular}{|l|r|r|r|r|}
\hline Discriminação por programas & $\begin{array}{l}\mathrm{N}^{\circ} . \\
\text { projetos }\end{array}$ & Área (ha) & $\begin{array}{l}\mathrm{N}^{\circ} . \\
\text { famílias }\end{array}$ & $\begin{array}{l}\text { Período do } \\
\text { contrato. }\end{array}$ \\
\hline Reforma Agrária Solidária - São José & 44 & $24.052,37$ & 688 & \multicolumn{1}{c|}{1997} \\
\hline Cédula da Terra & 114 & $72.484,81$ & 2.000 & $1997 / 2000$ \\
\hline Transição Cédula da Terra/Banco da Terra & 112 & $70.416,68$ & 1.590 & $2000 / 2003$ \\
\hline $\begin{array}{l}\text { Crédito Fundiário e Combate à Pobreza } \\
\text { rural }\end{array}$ & 27 & $15.302,01$ & 381 & $2002 / 2003$ \\
\hline Programa Nacional de Crédito Fundiário & 21 & $8.763,87$ & 258 & $2003 / 2004$ \\
\hline TOTAL & $\mathbf{3 1 8}$ & $\mathbf{1 9 1 . 0 1 9 , 7 4}$ & $\mathbf{4 . 9 1 7}$ & \\
\hline
\end{tabular}

Fonte: Seagri - CE/2004.

A Reforma Agrária de Mercado no Ceará, em seu primeiro ano de funcionamento (1997), adquiriu 44 imóveis, beneficiando 688 famílias. Porém, nos anos seguintes (1997 a 2000) deu um salto para 114 imóveis, beneficiando 2.000 famílias. A transição do Cédula da Terra para o Banco da Terra não inibiu o desenvolvimento do programa, e, assim, entre 2000 e 2003, foram implementados 112 projetos, beneficiando 1.590 famílias. O salto no número de projetos e de famílias beneficiadas com o Cédula da Terra e o Banco da Terra teve relação com a campanha eleitoral para a Presidência da República e a possibilidade, na época, de o governador Tasso Jereissati ser o candidato sucessor do então presidente Fernando Henrique Cardoso.

O Crédito Fundiário e Combate à Pobreza (2002 a 2004) adquiriu 35 imóveis, beneficiando 488 famílias. A queda dos números no programa está associada a um quadro de instabilidade presente na política de desenvolvimento rural do presidente Lula da Silva, eleito no final de 2002, e às constantes críticas feitas ao programa, seja por políticos, seja por intelectuais ou lideranças camponesas. A pressão feita pelos movimentos socioterritoriais foi fundamental para que a continuidade desse programa no Estado fosse repensada.

Embora se trate de uma mesma política de intervenção fundiária, os programas que compõem a proposta Reforma Agrária de Mercado distinguem-se quanto à elaboração e à estrutura, mas possuem a mesma leitura - a de que o desenvolvimento do campo passa pelo acesso dos pobres ao mercado e pela inexistência de uma questão agrária. Teoricamente, eles se assemelham por ser considerados programas de caráter complementar ao processo de desapropriação, de "alívio da pobreza" no campo e de 
descentralização da reforma agrária, com consequente transferência de poder para governos e municípios.

Com relação ao caráter da complementaridade, os programas de crédito fundiário revelaram supremacia. Ao comparar os programas de assentamentos rurais existentes no Ceará no período de 1995 a 2004, foi possível fazer uma análise sobre o desenvolvimento dos processos de aquisição de terras via desapropriação e via compra e venda de terras no mercado. O quadro 02 traz um resumo dessa constatação.

Quadro 02 - Ceará

Número de imóveis por programa

\begin{tabular}{|c|c|c|c|c|c|c|c|}
\hline \multirow[t]{2}{*}{ ANOS } & \multicolumn{7}{|c|}{ PROGRAMAS DE ASSENTAMENTOS } \\
\hline & IDACE* & INCRA* & PSJ & PCT & PBT & CFCP & PNCF \\
\hline 1995 & & 45 & & & & & \\
\hline 1996 & & 50 & & & & & \\
\hline 1997 & 28 & 46 & 44 & 7 & & & \\
\hline 1998 & & 53 & & 87 & & & \\
\hline 1999 & & 7 & & 13 & & & \\
\hline 2000 & & 17 & & 7 & 45 & & \\
\hline 2001 & 4 & 1 & & & 49 & & \\
\hline 2002 & 5 & 10 & & & 15 & 9 & \\
\hline 2003 & & 5 & & & 3 & 18 & \\
\hline 2004 & & 2 & & & & & 21 \\
\hline TOTAL & 37 & 236 & 44 & 114 & 112 & 27 & 21 \\
\hline
\end{tabular}

* Desapropriação

Fonte: Período: 01/01/1995 até 14/07/2004 - INCRA, 2004.

A partir de 1997, o Estado passou a contar com outros projetos (PSJ/PCT/PBT/CFCP e PNCF) para a constituição de assentamentos rurais, além dos processos já existentes, ocorrentes via desapropriação de terras feitas pelo INCRA e pelo IDACE. A novidade é que esses outros programas foram feitos com base no pressuposto de que se há um proprietário interessado em vender terras e camponeses sem-terra interessados em comprá-las, a situação propicia a negociação do processo no mercado de terras. O governo estadual, por intermédio do IDACE, reduziu significativamente os assentamentos via desapropriação de terra, investindo majoritariamente na reforma agrária com base no mercado. Os projetos de assentamento desenvolvidos pelo INCRA no Estado não acompanharam o andamento de projetos de assentamentos via mercado de terra. Dos 591 assentamentos criados, 54\% (318) foram de Reforma Agrária de Mercado, e os outros 46\% (273) foram de Reforma Agrária de Fato. Isso indica a supremacia dos programas de crédito fundiário no Estado a despeito do seu caráter de complementaridade. 
No quadro 03 mostra-se as áreas adquiridas nos diferentes programas de assentamentos rurais no Estado.

Quadro 03 - Ceará

Área (ha) dos imóveis por programa

\begin{tabular}{|c|r|r|r|r|r|r|r|}
\hline ANOS & \multicolumn{7}{|c|}{ PROGRAMAS DE ASSENTAMENTOS } \\
\hline & IDACE * & \multicolumn{1}{|c|}{ INCRA* } & PSJ & \multicolumn{1}{c|}{ PCT } & PBT & CFCP & PNCF \\
\hline 1995 & & $10.598,13$ & & & & & \\
\hline 1996 & & $128.296,67$ & & & & & \\
\hline 1997 & $25.010,17$ & $105.033,15$ & $24.052,37$ & $3.042,80$ & & & \\
\hline 1998 & & $110.516,97$ & & $58.526,46$ & & & \\
\hline 1999 & & $20.514,03$ & & $6.824,30$ & & & \\
\hline 2000 & & $25.108,78$ & & $4.091,25$ & $29.804,84$ & & \\
\hline 2001 & 824,27 & $1.680,54$ & & & $29.694,10$ & & \\
\hline 2002 & $2.415,53$ & $16.317,20$ & & & $10.061,73$ & $6.548,50$ & \\
\hline 2003 & & $8.078,85$ & & & 856,01 & $8.753,51$ & \\
\hline 2004 & & $9.924,08$ & & & & & $8.763,87$ \\
\hline TOTAL & $\mathbf{2 8 . 2 4 9 , 9 7}$ & $\mathbf{4 3 6 . 0 6 8 , 4 0}$ & $\mathbf{2 4 . 0 5 2 , 3 7}$ & $\mathbf{7 2 . 4 8 4 , 8 1}$ & $\mathbf{7 0 . 4 1 6 , 6 8}$ & $\mathbf{1 5 . 3 0 2 , 0 1}$ & $\mathbf{8 . 7 6 3 , 8 7}$ \\
\hline
\end{tabular}

Fonte: Período: 01/01/1995 até 14/07/2004; INCRA, 2004.

A área de assentamentos rurais no Estado era de 665.338,11 hectares. Os dados revelam que a maioria das terras, 70\% (464.318,37 ha), foi proveniente de processos de desapropriação ou de compra realizada pelo INCRA e pelo IDACE, via projetos de Reforma Agrária de Fato. A outra parte, 30\% (191.019,74 ha), foi adquirida por meio de programa de compra e venda de terras no mercado.

Quanto ao número de famílias assentadas pelos programas, o quadro 04 revela o seguinte:

Quadro 04 - Ceará

Número de famílias beneficiadas por programa

\begin{tabular}{|c|c|c|c|c|c|c|c|}
\hline \multirow[t]{2}{*}{ ANOS } & \multicolumn{7}{|c|}{ PROGRAMAS DE ASSENTAMENTOS } \\
\hline & IDACE * & INCRA* & PSJ & PCT & PBT & CFCP & PNCF \\
\hline 1995 & & 2.429 & & & & & \\
\hline 1996 & & 2.535 & & & & & \\
\hline 1997 & 511 & 2.741 & 698 & 98 & & & \\
\hline 1998 & & 2.601 & & 1.613 & & & \\
\hline 1999 & & 358 & & 191 & & & \\
\hline 2000 & & 521 & & 98 & 652 & & \\
\hline 2001 & 84 & 49 & & & 666 & & \\
\hline 2002 & 62 & 329 & & & 208 & 153 & \\
\hline 2003 & & 185 & & & 64 & 228 & \\
\hline 2004 & & 109 & & & & & 258 \\
\hline TOTAL & 657 & 11.857 & 698 & 2.000 & 1.590 & 381 & 258 \\
\hline
\end{tabular}

*Desapropriação.

Fonte: Período: 01/01/1995 até 14/07/2004; INCRA, 2004. 
Do total de famílias assentadas (17.441), 72\% delas (12.514) foram assentadas via processos de desapropriação de terra pelo INCRA e pelo IDACE, sob a lógica da reforma agrária de fato. Os outros 28\% (4.927 famílias) foram assentadas conforme a lógica que compõe a reforma agrária de mercado.

A partir de 1997, o governo do Estado reduziu o processo de criação de assentamentos, como previsto no Estatuto da Terra (1964) e na Constituição Federal (1988), enveredando para o processo de aquisição de terras no mercado. Considerando que o IDACE adquiriu apenas 37 assentamentos via desapropriação, contra 318 assentamentos sob a lógica do mercado, a Reforma Agrária de Mercado nem de longe se revelou como complementar ou alternativa, mas, sim, como forma de substituir e competir com o processo de desapropriação.

Com relação à área adquirida e ao número de famílias assentadas, o INCRA manteve índices bem melhores (70\% e 72\%, respectivamente) que os apresentados pelos programas de crédito fundiário (30\% e $28 \%$ respectivamente). Isso demonstra que o governo, por intermédio dessa política, centrou fogo no número de assentamentos, negligenciando área e número de famílias.

A respeito do alívio da pobreza, os assentamentos em sua maioria, a exemplo dos analisados por Alencar et al (2002) e Moura (2003), não estão conseguindo produzir o bastante para a alimentação familiar e muito menos gerar renda suficiente para pagar a terra. Esse fato tem levado os camponeses assentados a se envolverem em uma cadeia de endividamento de que dificilmente conseguirão sair.

Portanto, pequenos rendeiros, meeiros, moradores-de-condição e diaristas continuam sendo camponeses sem-terra, e, além de desterrados, endividados. A simples assinatura de um termo de compromisso de compra e venda da terra não gera para os assinantes o direito de propriedade. Dessa forma, se a terra não for paga, ela retornará para o banco financiador. Para o campesinato, não é possível se falar em alívio da pobreza com dívida no banco.

\section{4 - O caráter rentista do processo}

Com referência ao processo de descentralização da reforma agrária, o governo do Estado conseguiu, na prática, transferir o poder de decisão da reforma agrária para as elites rentistas locais, que passaram a dispor do poder de determinar as terras das quais desejavam dispor para a reforma agrária e de atribuir-lhes o preço de venda. Dessa 
forma, houve o fortalecimento da corrupção. Não foi difícil encontrar associações formadas por proprietários interessados em se livrar de terras ocupadas por posseiros e rendeiros, ou, também, deparar com políticos e proprietários rentistas locais aliados à constituição de associações. E, ainda, o governo do Estado premiou os proprietários rentistas falidos, propiciando a geração de renda capitalizada para meia dúzia de proprietários de terra e capitalistas donos de pequenos comércios localizados nos centros das cidades.

A dinamização que os programas de crédito fundiário causaram no mercado de terras nos municípios beneficiados pode ser observada nos depoimentos dos proprietários das terras vendidas.

Ao questionar sobre o porquê da venda da Fazenda Almécegas em Acaraú, o proprietário rentista revelou o que fez com o dinheiro e, ainda, a exploração do trabalho camponês feita na terra mantida como reserva de valor:

Foi vendida, pela parte financeira, deficiência financeira foi uma das causas. E, também, para ajudar os próprios moradores que estavam na terra, que já eram antigos, o intuito maior foi esse. Hoje eles são donos, é outra história. O intuito maior foi esse. Mas deu também para melhorar a loja. E, com a venda lá, implementou mais um pouco. Deu para pagar umas contas que já estavam em atraso e ampliar o comércio (Proprietário de terra, 47 anos, Acaraú/CE, 2002).

Nesse caso, o proprietário rentista relatou como se dá o processo em que a terra mantida como reserva de valor é instrumento de exploração do trabalho camponês. Em seu discurso, com base na lógica da troca de favor, o proprietário mostrou como tem se estabelecido a produção do capital via mercado de terras.

Em outra entrevista, o proprietário da Fazenda Curral Velho esclareceu a lógica da especulação imobiliária que se estabeleceu no campo.

Vendi porque eu vivo nesse ramo de vida. É comprar e vender qualquer coisa. Que seja gado, que seja terreno, que seja carro. Então, eu já comprei vários terrenos, e continuo vendendo quando dá certo vender. Vendi porque eu vivo nesse ramo de vida. É comprar e vender qualquer coisa. Que seja gado, que seja terreno, que seja carro. Então, eu já comprei vários terrenos, e continuo vendendo quando dá certo vender. Essa fazenda eu comprei por cinquenta mil reais e trinta e cinco réis (cabeças de gado); com pouco tempo achei oitenta e cinco mil reais. Agora mesmo eu estou com dezesseis fazendas, tudo aqui em Acaraú, É Curral Velho, Cauassu, Carrapicho, Ilha do Rato, tudo por aqui (Proprietário de terra, 62 anos, Acaraú/CE, 2002). 
Nesse caso, o proprietário rentista é o rentista, o agente imobiliário, preparado para vender e comprar a mercadoria - a terra. A concepção de propriedade privada da terra faz dela uma mercadoria com alto valor no mercado brasileiro. Conforme Oliveira (2001), a terra, mantida nas mãos da elite fundiária, econômica e política, atua como reserva de valor e/ou reserva patrimonial e tem a função de gerar renda capitalizada para os proprietários de terra rentistas.

Outra situação encontrada foi a da transferência da renda capitalizada do campo para os investimentos na cidade.

\begin{abstract}
A terra era herança, e há cinco anos venho tentando investir na criação de gado. Fiz um empréstimo no banco, mas não consegui pagar. Por isso, vendi a terra. Com o dinheiro da venda da terra, melhorei o comércio (mercadinho) e ampliei o número de cabeças de gado numa outra fazenda (Proprietário de terra, 37 anos, Canindé/CE, 2003).
\end{abstract}

Em todos os casos, proprietários rentistas falidos puderam, com a venda de suas terras, fazer novos investimentos na cidade e/ou no campo, ou seja, a produção do capital no campo cearense continua acontecendo com base na renda capitalizada da terra, o que vem confirmar o caráter rentista da terra no Brasil.

A transferência da renda da terra para investimentos urbanos ocorre com frequência na agricultura brasileira. Sá Jr. (1976) ao analisar o desenvolvimento da agricultura nordestina nas décadas de 1950 e 1960, salientou que o fenômeno de expansão do número de pequenos arrendatários-rendeiros, ocorrido naquele momento, era um importante mecanismo de drenagem da renda da agricultura para atividades de outros setores, já que os proprietários que arrendavam suas terras aplicavam muitas vezes sua renda fora do setor agrícola.

A drenagem da renda da terra para o setor urbano não é nenhuma novidade. $\mathrm{O}$ que é novo é a mundialização do capital e a tentativa de tornar também mundial a mercadoria terra e seu potencial de gerar renda capitalizada para diferentes grupos de proprietários de terras e capitalistas rentistas, simultaneamente, em vários países do mundo.

\title{
5- Considerações Finais
}

De maneira geral, a implementação da Reforma Agrária de Mercado no Ceará tem, por um lado, reativado o mercado de terras, contribuindo para a ampliação das 
relações especificamente capitalistas no campo, como a compra e venda de terras. Por outro lado, os assentamentos têm se mostrado como espaços da não sujeição, da não expropriação da renda da terra pelo patrão e da continuidade das relações de origem não capitalistas no campo, como o trabalho familiar, a prática de ajuda mútua ou o uso comum das terras soltas.

Esse quadro revela na figura do camponês assentado que a lógica do desenvolvimento do campesinato está no seio da lógica capitalista. E à Geografia cabe o estudo dessa realidade contraditória, desigual e combinada, com base na análise do território como produto concreto da luta de classes travada no cotidiano da sociedade capitalista e dos assentamentos rurais na forma de frações desse território conquistadas pelos camponeses, no processo de luta pela terra e pela reforma agrária.

\section{6 - Bibliografia}

ALENCAR, Francisco Amaro Gomes de. Caminhos e descaminhos da "reforma agrária" no Ceará. Fortaleza:[s.n.], 2000.

. Uma geografia das políticas fundiárias no estado do Ceará. Fortaleza, 2005. 297p. Tese (doutorado em Sociologia). Departamento de Ciências Sociais e Filosofia, UFC.

ALENCAR. Francisco Amaro Gomes de. et al. Programa Cédula da Terra: o caso do Ceará. Fortaleza: ABRA, CPT, APR, FIAN-Brasil, MST e REDE Brasil [s.n.], 2002. 52p.

BINSWANGER, Hans. A reforma agrária assistida pelo mercado: o novo enfoque do Banco Mundial. Trad. José Nelson Bessa Maia. [s.n.t.] [1996?]. 5p.

BRANDÃO, Wilson. A reforma agrária solidária do Ceará. In: LEITE, Pedro Sisnando et al. (orgs.). Reforma agrária e desenvolvimento sustentável. Brasília: MDA, Paralelo 15, NEAD, 2000. Pp. 317 - 327.

MORAIS, Jomar. Revolução silenciosa - sem choques, o Banco da Terra vira um modelo internacional de reforma agrária capitalista. In: Revista Exame. 26/07/ 2000. p.32/3.

MOURA, Antônio Marcos Pontes de. "A porteira está aberta": o programa de reforma agrária solidária - Cédula da Terra no Estado do Ceará. Aracaju, SE, 2003. 63p. Dissertação (mestrado em Geografia), Núcleo de Pós Graduação em Geografia, UFS.

OLIVEIRA, Alexandra Maria de. A contra-reforma agrária do banco mundial e os camponeses no Ceará. São Paulo, 2005. 379 f. Tese (Doutorado em Geografia Humana) - Faculdade de Filosofia, Letras e Ciências Humanas/USP, São Paulo, 2005. 
OLIVEIRA, Ariovaldo Umbelino de. A longa marcha do campesinato brasileiro: movimentos sociais, conflitos e reforma agrária. Revista Estudos Avançados. São Paulo: 15 (43), 2001. pp. 185 - 206.

SÁ JR., Francisco. O desenvolvimento da agricultura nordestina e a função das atividades de subsistência. Estudos Cebrap III. $2^{\text {a }}$ edição. São Paulo: Editora Brasiliense /Edições Cebrap, 1976. Pp. 79 - 134.

SANTANA, Eudoro. Modelo inusitado está levando no bico. Jornal O Povo. Fortaleza, 12/08/1997. Caderno Opinião. p. 7A.

\section{Documentos}

BRASIL. GOVERNO FEDERAL. Ministério do Planejamento e Orçamento - Projeto Áridas. Nordeste: uma estratégia de desenvolvimento sustentável. Brasília: 1995. 231p.

.Ministério da Política Fundiária e da Agricultura Familiar. Programa Novo Mundo Rural. Brasília, DF. 1999. 26p.

. Ministério do Desenvolvimento Agrário - manual de operação do projeto Crédito Fundiário e Combate à Pobreza Rural. Brasília, 2002. 56p.

- Ministério do Desenvolvimento Agrário - manual de operação do programa Crédito Fundiário e Combate à Pobreza Rural, $2^{a}$ edição, Brasília, 2003. 26p.

- Ministério do Desenvolvimento Agrário - manual de operação do Programa Nacional Crédito Fundiário, Brasília, 2003. 23p.

CEARÁ. GOVERnO DO ESTADO. Manual de operação. Projeto São José Combate à pobreza no interior do Ceará. Fortaleza, 1987. 12p.

Fortaleza, 1996. 08p. . Manual de operação. Reforma Agrária Solidária. . Manual de operação. Reforma Agrária Solidária Cédula da Terra. Fortaleza, 1997.12p. 